Rev. Adm. Saúde - Vol. 18, № 70, jan. - mar. 2018

http://dx.doi.org/10.23973/ras.70.78

EDITORIAL

\title{
Gestão da qualidade em saúde
}

\author{
Haino Burmester ${ }^{1}$
}

1. Médico, administrador hospitalar e de sistemas de saúde. Coordenador do Programa CQH

Ao se analisar as metodologias utilizadas hoje na busca por melhoria da qualidade em instituições de saúde, se verá que elas em pouco diferem daquilo que nos Estados Unidos já se faz há mais de 20 anos e, ainda assim, não com muito sucesso. O que se faz parece nada mais do que meros rearranjos das mesmas propostas, às vezes, apresentadas de maneira diferente ou com o linguajar mais rebuscado e presunçoso da modernidade. (não se sabe ainda se o, chamado, "Obamacare" modificou isso ou se Trump vai conseguir). Ou seja, há tempos se busca, talvez, em lugares errados, como alcançar qualidade na assistência à saúde quando a resposta para essa busca possa estar bem diante de todos sem chamar a atenção dada a sua falta de atrativos glamorosos ou justificativas para demonstrações eruditas. Não será nas velhas e boas práticas gerenciais e assistenciais que se encontrará a qualidade? Esta pergunta não se constitui numa demonstração de saudosismo ou não aceitação da inovação muito menos de cabotinismo ou versão conservadora, tipo "donos da verdade". A afirmação está baseada no fato de que gestores de todas as esferas do setor saúde estão empenhados em procurar a fonte da sabedoria que lhes conduzirá ao paraíso; não existe tal fonte em nenhuma das propostas inovadoras e modernas que pretendem fornecer a fórmula mágica para a felicidade. Às vezes a pirotecnia da "moderna administração" serve principalmente para esforços mercadológicos e de promoção pessoal ou organizacional mais do que para resolver os problemas da qualidade nas organizações de saúde. Não são soluções pontuais e momentâneas que trarão a qualidade certificada ou acreditada. A verdade é uma só: o caminho para a qualidade é cheio de obstáculos e dificuldades que serão vencidos com trabalho árduo e persistente na busca incessante por melhoria dos processos de atendimento e de gestão. Não será atuando apenas na resolução dos problemas após sua ocorrência nem basear propostas no conjunto de soluções encontradas para resolver os problemas acontecidos, mas se antecipando a eles. $E$ isto só se consegue com uma proposta integrada, sistêmica e coerente de um sistema que harmonize gestão e assistência mediante práticas configuradas dentro de uma proposta que entenda a organização como um 
todo que deve ser gerenciado tecnicamente. Esta proposta se antecipa aos problemas; é proativa e busca criar condições para que, se possível, os problemas não ocorram. É por este caminho que, este artigo sugere se deve trilhar para alcançar a qualidade almejada.

O artigo está alinhado com a tese de que a qualidade virá como consequência de uma ação gerencial integrada, sistêmica e coerente. Ações gerenciais praticadas dentro de um sistema de gestão e de um modelo assistencial definidos e claros. O artigo advoga que a gestão é uma técnica que se aprende e exercita como em todas as demais ciências que permeiam a atividade humana. Trata-se de uma ciência e de uma técnica baseada em princípios, desenvolvidos por diferentes escolas de pensamento e que são necessárias para ordenar a atividade de qualquer grupo humano que se reúna para realizar alguma coisa junto.

O texto se cinge ao aspecto micro do atendimento, ou seja, aquele prestado nas unidades, como hospitais, clinicas ou ambulatórios. Não se está, portanto, descartando o papel que a organização do sistema macro tenha sobre a qualidade nas suas unidades, mas apenas que o enfoque é nas unidades prestadoras de assistência e sobre a forma de alcançar qualidade nelas; é disso que trata o artigo. Está baseado na apresentação de um sistema de gestão para direcionar também o modelo assistencial nos hospitais como forma de se alcançar mais qualidade para essas organizações. É preciso entender a importância da padronização das ações como base para aplicação deste sistema. O sistema gerencial e assistencial deverá contemplar:

- elementos ligados com a liderança do hospital;

- elementos ligados ao planejamento estratégico, de maneira a conduzir o hospital a uma administração estratégica;

- aspectos ligados ao marketing e à epidemiologia, de maneira que o hospital se preocupe com seus clientes, com as prevalências das doenças a que irá prestar assistência e, portanto, com o mercado no qual está inserido (mesmo hospitais públicos têm que se preocupar com o mercado no qual atuam);

- aspectos ligados à informação como elemento necessário para a análise crítica dos resultados e seus resultados como subsídios para o planejamento;

- a gestão do recurso humano, nuclear na realização de todas as ações no hospital;

- e, por fim, a gestão dos processos de atendimento realizados no hospital, ou seja, seu modelo assistencial.

O que se advoga aqui, portanto, é que diante da miríade de interesses envolvidos na assistência hospitalar e das inúmeras possibilidades de manipulações emocionais, comerciais, científicas e de outras naturezas apresentadas por ela, o mais correto para buscar qualidade parece ser a busca 
do equilíbrio entre as ações desencadeadas pelo modelo assistencial e pelo modelo gerencial da organização sem considerações de outras naturezas que possam interferir com o melhor para pacientes, familiares, prestadores e para a comunidade como um todo. Sem atender à filigranas periféricas à essência do atendimento, concentrar-se na substancia do mesmo com racionalidade, ética, sentimentos humanos, capacidade técnica e obstinação por fazer o melhor dentro dos limites da razoabilidade e da tecnologia disponível sem dramaticidade nem heroísmos infrutíferos nem buscando auto promoção, remunerações indevidas ou outros benefícios espúrios. Para isso devem-se deixar de lado modismos passageiros e pirotecnias mercadológicas buscando nas velhas e boas práticas da gestão e da assistência a resposta para os desafios que se apresentam. Isto não significa uma atitude passiva diante dos avanços e inovações da medicina e da gestão, mas a boa assistência hospitalar tem de estar solidamente baseada em conceitos e valores claros e definidos e não ser sublevada pelas marés do momento ou pelos "sábios" de ocasião; só assim ela poderá obter o máximo benefício disponível pela incorporação da tecnologia hoje existente.

Falar de qualidade em hospitais hoje, portanto, significa falar em algo que possa englobar todos os requisitos apresentados numa abordagem sistêmica, integrada e coerente; em outras palavras, num modelo de gestão, que tenha como consequência a excelência na assistência, como têm apregoado os teóricos da moderna administração. É preciso, portanto, não ceder ao fascínio de modismos e enfrentar a dura realidade de que qualidade se consegue com trabalho perseverante e constância de propósitos. A qualidade é consequência de uma ação resoluta da liderança da organização buscando a excelência com dedicação e método. Exige ação continuada sem esmorecimentos porque os caminhos difíceis é que levam às grandes realizações. Resultados não vêm num passe de mágica, mas sim são conquistados ao longo do tempo num trabalho que pressupõem recaídas e retomadas; trata-se de um processo sem fim. Diz-se que a excelência vem como resultado de uma corrida sem linha de chegada; sempre haverá novos patamares a serem vencidos, novos obstáculos a serem superados. Quem acredita que alcançou sua "qualidade desejada", já começou a perdê-la. Por isso um dos pré-requisitos para alcançá-la é a humildade de saber que sempre há algo novo para ser alcançado; que não se sabe tudo e que se deve continuar sempre buscando; que sempre se pode fazer melhor não importa em qual estágio se encontre a organização; e que sempre haverá alguém fazendo as coisas melhor do que nós. Tolstoi dizia que a perfeição é impossível sem humildade: "por que hei eu de lutar pela perfeição se já sou suficientemente bom?"

Por isso é que se entende como uma ferramenta mais útil para materializar este desiderato um modelo de gestão sistêmico, integrado e coerente; é o método que se necessita para orientar o raciocínio do gestor no sentido de darIhe um norte para sua ação. A implantação deste modelo demanda tempo e acompanhamento, antes que resultados possam ser contabilizados. Trata-se, de incorporar técnicas de gestão ao segmento da saúde, mesmo em hospitais públicos; estas técnicas podem e devem ser copiadas de outros ramos da atividade econômica. Estudo recente, encomendado pelo Congresso dos EUA, sobre reforma do sistema de saúde naquele país, tinha, como uma de suas 
primeiras recomendações, o uso de técnicas gerenciais bem-sucedidas fora do setor saúde.

Na gestão dos processos está a maior diferença do hospital com empresas de outras áreas da atividade econômica. Afora os processos tudo que se faz em uma organização qualquer, do ponto de vista gerencial, também se faz (ou se deveria fazer) em hospitais. Os conceitos de: liderança, planejamento, marketing, as relações com a sociedade, gestão das informações e gestão das pessoas são válidos e aplicáveis de maneira igual em qualquer organização.

São necessárias ações concretas para orientar hospitais na sua preocupação com qualidade. Talvez a principal seja englobar todas as iniciativas existentes no hospital, dentro de um sistema de qualidade que não seja atribuição específica de nenhuma pessoa, nem de nenhum grupo, mas preocupação de toda a instituição, pois qualidade é consequência de uma ação coletiva e não do "departamento da qualidade", ou da "gerência de qualidade", ou do "grupo da qualidade", ou de qualquer outra denominação que se queira dar para algumas pessoas que teriam a preocupação com o tema; aliás, o tema deve ser preocupação de todos e, portanto, não se recomenda abrigá-lo em nenhum departamento da organização, mas sempre tratá-lo de maneira institucional. Se apenas um grupo do hospital for responsabilizado pela qualidade os demais se considerarão desobrigados de buscá-la; por que se preocupar com algo quando existe um setor específico para isso? Os demais considerarão que qualidade não precisa ser uma preocupação deles. Nesta visão, o "gerente de qualidade" ou o "gestor da qualidade" do hospital tem que ser o principal executivo da organização.

Recebido: 15 de dezembro de 2017. Publicado: 11 de janeiro de 2018

Correspondência: Haino Burmester. Avenida Brigadeiro Luís Antônio, 278 - $7^{\text {o }}$ andar. CEP 01318-901. São Paulo - SP. E-mail: cqh@apm.org.br

(C) This is an Open Access article distributed under the terms of the Creative Commons Attribution License, which permits unrestricted use, distribution, and reproduction in any medium, provided the original work is properly cited 